\title{
Curva de embebição, anatomia e mobilização de reservas em sementes de Mimosa flocculosa submetidas à superação de dormência
}

\author{
Maiara ladwizak Ribeiro,"* (D), Guilherme de Almeida Garcia Rodrigues ${ }^{2}$ (D), \\ Ana Paula Bazzanella ${ }^{3}$ (D), Shirley Martins ${ }^{3}$ (i), Jaqueline Malagutti Corsato 4 (i) \& \\ Andréa Maria Teixeira Fortes ${ }^{3}$ \\ 'Instituto de Botânica, Avenida Miguel Stéfano, 3687, Água Funda, 04301-902 São Paulo, SP, Brasil \\ *Autor para correspondência: maiara.iadwizak@gmail.com \\ ${ }^{2}$ Universidade Federal de Santa Catarina, Rua Engenheiro Agrônomo Andrei Cristian Ferreira, s/n, Trindade, \\ 88040-900 Florianópolis, SC, Brasil \\ 3Universidade Estadual do Oeste do Paraná, Rua Universitária, 1619, Universitário, 85819-170 Cascavel, PR, Brasil \\ ${ }^{4}$ Univel Centro Universitário, Av. Tito Muffato, 2317, Bairro Santa Cruz, 85806-080 Cascavel, PR, Brasil
}

Recebido 29.IV.2019

Aceito 10.VI.2021

DOI 10.21826/2446-82312021v76e2021016

\begin{abstract}
RESUMO - O trabalho teve como objetivo ampliar o conhecimento sobre a germinação de Mimosa flocculosa Burkart e eficiência dos tratamentos de superação de dormência com foco na embebição, mobilização de reservas, anatomia tegumentar e germinação das sementes. Foi realizada a curva de embebição e a partir desta, foi estipulado o perfil trifásico para os três tratamentos: controle, água a $80^{\circ} \mathrm{C}$ por 10 minutos e ácido sulfúrico $98 \%$ por três minutos. Foram analisados durante a embebição os açúcares, proteínas e anatomia tegumentar das sementes, junto com a germinação, verificando: porcentagem, frequência e sincronização da germinação. Nossos resultados demonstraram que os dois métodos utilizados de superação de dormência nas sementes de M. flocculosa são indicados, pois estimularam uma curva de embebição mais uniforme, maior degradação de açúcares e proteínas, o tegumento destes tratamentos apresentou fissuras e desestruturações auxiliando a entrada de água, elevando a germinação e com tendência à sincronização.
\end{abstract}

Palavras-chave: espécie nativa, germinação, tegumento duro

\begin{abstract}
Imbibition curve, anatomy and mobilization of reserves in seeds of Mimosa flocculosa Burkart submitted to overcoming of dormancy. This study aimed to expand knowledge about Mimosa flocculosa Burkart seed germination and efficiency of break dormancy treatments, focusing on hydration, reserves mobilization, integument anatomy and seed germination. We conducted a hydration curve, and from that, we stipulated a three-phase profile for each treatment: control, water at $80^{\circ} \mathrm{C}$ for $10 \mathrm{~min}$ and sulfuric acid $98 \%$ for $3 \mathrm{~min}$. Sugars and proteins, integumentary anatomy and germination parameters (germination percentage, frequency and synchrony of germination) were analyzed during hydration. Our results showed that the overcoming dormancy methods used in M. floculosa seeds are indicated, since they improved germination, uniformed hydration, presented integument fissures and destabilizations increasing water uptake and germination synchrony.
\end{abstract}

Keywords: native species, germination, hard integument

\section{INTRODUÇÃO}

O Brasil é um dos maiores detentores de diversidade de espécies nativas a nível mundial, porém, essa vegetação sofre constantemente com o aumento populacional, comércios madeireiros e a expansão de cidades. Com isso, eleva-se o número de áreas degradadas e muitas espécies nativas possuem seu número reduzido fazendo com que as sementes sejam essenciais para propagação e perpetuação das espécies (Carvalho \& Nakagawa 2012, Monteiro et al. 2018).

Nesse contexto, cada vez mais surgem tentativas de preservação e meios de recuperação de áreas, principalmente empregando espécies nativas de diferentes estágios da sucessão ecológica: pioneiras, secundárias, clímax, possibilitando que essas áreas voltem o mais próximo de sua condição natural, na tentativa de restaurar a biodiversidade outrora existente (Kageyama et al. 2003, Fonseca \& Venticinque 2018).

Um dos processos fisiológicos mais importante para a recuperação de áreas e perpetuação das espécies vegetais é a germinação de sementes, em que a partir do início da aquisição de água, as sementes reativam seu metabolismo basal, utilizam suas reservas energéticas estocadas e realizam vários processos metabólicos durante a embebição que juntos resultam na germinação (Marcos-Filho 2015).

É no perfil trifásico da embebição que ocorrem processos importantes, na fase I ocorre a rápida entrada de água na 
semente e com isso, o reparo do sistema de membranas, aumento da respiração e a reativação do metabolismo celular. Já na fase II, a velocidade com que a água entra na semente é lenta e essa fase é caracterizada pelo metabolismo bioquímico ativo, tendo síntese de enzimas, aumento da mobilização de reservas e início do alongamento celular. $\mathrm{Na}$ fase III ocorre a crescimento do embrião, junto com a continuidade da mobilização de reservas e emergência da raiz primária (Bewley et al. 2013, Oliveira \& Bosco 2013).

A mobilização de reservas que ocorre durante a embebição é fundamental para o desenvolvimento do embrião e das plântulas, pois fornece energia para as atividades metabólicas. As principais fontes de reservas existentes são: carboidratos, lipídios e proteínas. Com isso, vários trabalhos vêm sendo realizados observando a mobilização de reservas nas sementes, especialmente em espécies nativas utilizadas para a recuperação de áreas degradadas, onde essas análises auxiliam na obtenção de mais informações sobre o manejo correto das espécies (Corte et al. 2006, Bewley et al. 2013, Furtado 2014).

Entretanto, algumas espécies apresentam alguns mecanismos que inviabilizam a aquisição de água pelas sementes. Um exemplo é a dormência, que é um mecanismo que permite a longevidade das espécies, sendo uma característica evolutiva benéfica, pois distribui a germinação ao longo do tempo e espaço fazendo com que a semente germine apenas em condições favoráveis também para o desenvolvimento e estabelecimento da plântula no ambiente (Baskin \& Baskin 2004). São cinco as classes de dormência existentes sendo elas: fisiológica, morfológica, morfo-fisiológica, física e química (Cardoso 2009). Dentre essas, a dormência física, também chamada de dormência tegumentar é encontrada em mais de um terço das espécies nativas. Esse tipo de dormência é característica de sementes que apresentam tegumento rígido, impermeável a água e que diminui as trocas gasosas do embrião com o meio, sendo encontrada na maioria dos membros da família Fabaceae (Alexandre et al. 2009).

Para os viveiristas a dormência acaba dificultando o desenvolvimento de mudas, assim, tratamentos de superação de dormência auxiliam na produção. Com isso, vários métodos de superação de dormência são utilizados, entre eles para a dormência física, destacam-se a utilização de água aquecida e escarificação ácida. Para garantir o sucesso desses tratamentos são necessárias pesquisas em diferentes espécies, buscando descobrir a eficiência, melhores tempos e temperaturas da água a serem utilizadas, observando principalmente seu efeito na germinação e sincronização (Monteiro et al. 2018).

Uma espécie que possui dormência física é a Mimosa flocculosa Burkart, conhecida popularmente como bracatinga de campo-mourão. É uma espécie pioneira da família Fabaceae, possui crescimento rápido em conjunto com muitas folhas que são depositadas nos ambientes. Aumentando a utilização dessa espécie nativa em recuperação de áreas e solos degradados (Shibata et al. 2014, Shibata et al. 2017).
Buscou-se neste trabalho ampliar o conhecimento sobre a fisiologia da germinação das sementes de Mimosa flocculosa e a eficiência de alguns tratamentos de superação de dormência, tendo como foco a embebição, quantificação de mobilização de reservas, a anatomia do tegumento e a germinação das sementes.

\section{MATERIAL E MÉTODOS}

Os experimentos foram conduzidos de dezembro de 2017 a fevereiro de 2018 no Laboratório de Fisiologia Vegetal da Universidade Estadual do Oeste do Paraná Unioeste. Foram utilizadas sementes de Mimosa flocculosa doadas pelo Laboratório de Análise de Sementes do Instituto Ambiental do Paraná - IAP, sendo as sementes coletadas no ano de 2017 na cidade de Campo Mourão.

\section{Teor de água das sementes e métodos de superação de dormência}

O teor inicial de água das sementes foi determinado com quatro repetições de 25 sementes cada, sendo estas pesadas em balança de precisão de $0,0001 \mathrm{~g}$ e secas pelo método de estufa a $105^{\circ} \mathrm{C}$ por 24 horas (Brasil 2013).

Para curva de embebição, germinação, anatomia e mobilização de reservas, as sementes foram submetidas aos seguintes tratamentos: Controle (sem nenhum tratamento), submersão em água destilada a $80{ }^{\circ} \mathrm{C}$ por 10 minutos mantida em temperatura ambiente até esfriar e submersão em ácido sulfúrico $\left(\mathrm{H}_{2} \mathrm{SO}_{4}\right)$ P.A. $98 \%$, durante 3 minutos e posteriormente lavadas em água corrente durante cinco minutos. Não foi utilizado tratamento fitossanitário nas sementes. O número de sementes e repetições está descrito em cada um dos processos abaixo.

\section{Curva de embebição e pontos de coleta para mobilização de reservas e anatomia do tegumento das sementes}

Para a curva de embebição, foram utilizadas quatro repetições de 100 sementes para cada um dos três tratamentos. As sementes foram dispostas em rolo de papel toalha para germinação umedecido com água destilada em volume equivalente a 2,5 vezes o seu peso e então acondicionadas em câmara de germinação do tipo B.O.D a $25{ }^{\circ} \mathrm{C}$ com variação de $2{ }^{\circ} \mathrm{C}$ e fotoperíodo de 12 horas de luz e 12 horas de escuro.

Para cada pesagem as sementes eram retiradas do papel e pesadas em balança de precisão para obtenção da massa úmida das sementes em cada período. Nas primeiras 34 horas de experimento as avaliações foram realizadas a cada hora, desse período até as 58 horas feitas a cada duas horas, posteriormente a cada 12 horas até as 94 horas e após esse período a cada 24 horas até as 166 horas de experimento. A avaliação da aquisição de água pelas sementes foi realizada até que pelo menos $50 \%$ das sementes germinassem.

Analisando o comportamento das curvas de embebição foram definidos pontos de coleta das sementes, baseado no padrão trifásico de hidratação. Os períodos definidos estão apresentados na Tabela 1. 
Tabela 1. Períodos da embebição, em horas, para os tratamentos controle, água a $80{ }^{\circ} \mathrm{C}$ e ácido sulfúrico $98 \%$

\begin{tabular}{|c|c|c|c|}
\hline Tratamentos/ Períodos de Embebição & Controle & Água a $80^{\circ} \mathrm{C}$ & Ácido sulfúrico $98 \%$ \\
\hline Início da embebição & 0 horas & 0 horas & 0 horas \\
\hline Meio da fase I & 8 horas & 6 horas & 3 horas \\
\hline Início da fase II & 14 horas & 12 horas & 6 horas \\
\hline Meio da fase II & 26 horas & 18 horas & 8 horas \\
\hline Início da fase III & 38 horas & 25 horas & 11 horas \\
\hline
\end{tabular}

Baseado nesses períodos da curva foram realizadas as coletas para mobilização de reservas em todos os períodos descritos acima e para a anatomia do tegumento das sementes de M. flocculosa os períodos iniciais de cada fase: Início da fase I, II e III.

\section{Anatomia tegumentar}

Para análise anatômica, cada coleta contou com cinco sementes de cada tratamento Controle, Água a $80^{\circ} \mathrm{C}$ por 10 minutos e $\mathrm{H}_{2} \mathrm{SO}_{4}$ por 3 minutos. As sementes foram fixadas em FAA 50\% (Johansen 1940) e conservadas em álcool $70 \%$. Posteriormente, as sementes foram submetidas a desidratação em série etílica e inclusão em historesina Leica (de acordo com as orientações do fabricante), sendo realizadas secções transversais e longitudinais $(5 \mu \mathrm{m}$ de espessura) com auxílio de micrótomo rotativo (Leica RM 2245). As secções foram coradas com azul de toluidina a $0,05 \%$ (O'Brien et al. 1964) e montadas em lâminas permanentes com Entellan. As imagens das secções foram capturadas com auxílio do Fotomicroscópio Olympus Bx70, utilizando o programa DP Controller.

\section{Quantificação da mobilização de reservas}

Para a quantificação, em cada uma das coletas foram retiradas quatro repetições com 50 sementes de M. flocculosa, congeladas em nitrogênio líquido de forma a paralisar a atividade metabólica para posterior análises. Sendo o delineamento experimental inteiramente casualizado em esquema fatorial duplo (3 tratamentos x 5 períodos da curva de embebição).

Foram quantificados os açúcares solúveis totais (AST), açúcares redutores (AR), sacarose e as proteínas albuminas, globulinas, prolaminas e glutelinas. Para determinação de açúcares, a extração foi realizada de acordo com Garcia et al. (2006), sendo feitas três extrações exaustivas com álcool $80 \%$ durante 20 minutos. O sobrenadante das amostras foi utilizado para a quantificação de AST e sacarose, sendo empregado o reagente antrona, conforme Morris (1948) e Passos (1996), já para os AR foi utilizado o reagente DNS, conforme Miller (1959).

Para a determinação das proteínas, foi realizada extração seriada de acordo com Suda e Giorgini (2000), em que as proteínas foram extraídas conforme sua solubilidade. Dessa forma, a albumina foi extraída com água destilada, globulina com cloreto de sódio a $5 \%$, prolaminas com etanol $60 \%$ e glutelinas com hidróxido de sódio a $0,4 \%$. Para cada extração as amostras foram homogeneizadas com o solvente e após 24 horas foi realizada a centrifugação para extração da proteína. Para a quantificação das proteínas, foi utilizado o método de Bradfort (1976) com o reagente Coomassie Blue. As leituras de absorbância para a quantificação dos açúcares e proteínas foram medidas em espectrofotômetro.

\section{Teste de germinação}

Paralelamente à curva de embebição foi instalado o teste de germinação, segundo Brasil (2013), onde as sementes foram acomodadas em rolos de papel toalha para germinação umedecidos com água destilada em 2,5 vezes o seu peso seco sendo colocadas posteriormente em câmara de germinação do tipo B.O.D, com temperatura de aproximadamente $25^{\circ} \mathrm{C}$ e alternância de fotoperíodo a cada 12 horas entre claro e escuro.

Cada tratamento foi constituído de quatro repetições de 50 sementes por parcela, sendo utilizado o delineamento experimental inteiramente casualizado. A contagem de sementes germinadas foi realizada diariamente até o $14^{\circ}$ dia após a instalação do teste (Brasil, 2013), sendo consideradas germinadas aquelas sementes que apresentaram comprimento de raiz primária igual ou superior a $2 \mathrm{~mm}$ (Hadas 1976). Sendo analisadas as variáveis: porcentagem de germinação, frequência e sincronização da germinação (U), segundo Labouriau \& Valadares (1976).

\section{Análise estatística}

Os dados dos testes fisiológicos (germinação e sincronização) e bioquímicos (quantificação da mobilização de reservas), foram submetidos ao teste de homogeneidade de variâncias Levene a 5\% e ao teste para a normalidade dos resíduos Shapiro-Wilk a 5\%. Atendendo ao pressuposto de $\mathrm{p}>0,05$ os dados então foram submetidos a análise de variância ANOVA e as médias dos tratamentos foram comparadas pelo teste de Skott-Knott a 5\% de probabilidade, utilizando o programa RStudio 3.2.2.

\section{RESULTADOS}

\section{Teor de água e curva de embebição}

O teor de água inicial das sementes de Mimosa flocculosa era de $7,3 \%$. Nas sementes do controle, observamos que o ganho de água ocorreu com maior velocidade até as 13 horas, sendo que essas sementes tiveram um aumento de $8 \%$ quando comparadas ao início da do processo de embebição (Fig. 1). 


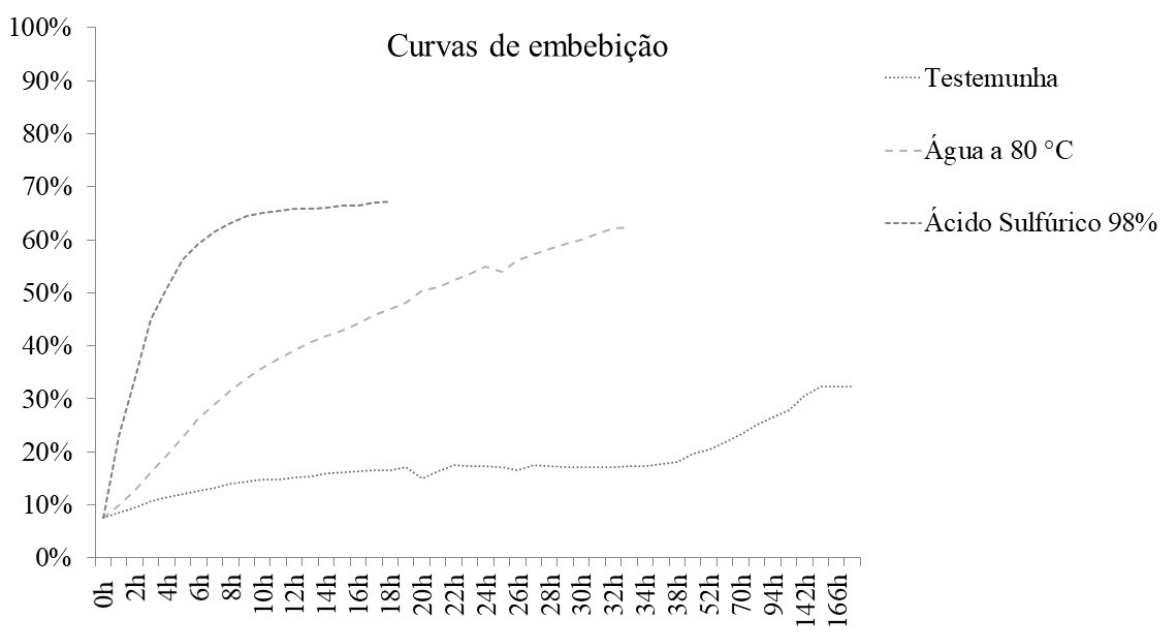

Figura 1. Teor de água (\%) das sementes de Mimosa flocculosa, submetidas aos tratamentos (controle, água aquecida a $80{ }^{\circ} \mathrm{C}$ por 10 minutos e ácido sulfúrico 98\%) durante três minutos ao longo da sua embebição (horas).

Observamos que, as sementes que passaram pelos tratamentos de superação de dormência com a água a $80{ }^{\circ} \mathrm{C}$ por 10 minutos e ácido sulfúrico $98 \%$ por três minutos, tiveram maior absorção de água e ganho de massa com maior velocidade nas primeiras 11 e 5 horas respectivamente, quando comparadas ao controle. E nestes tratamentos, ao final da fase I, o teor de água encontravase respectivamente $31 \%$ e $51 \%$ maior do que no início da embebição (Fig. 1).

Já a fase II (Fig. 1), para todos os tratamentos, foi caracterizada por uma diminuição na velocidade de hidratação da semente. Observamos que essa fase para as sementes do controle ocorreu das 14 até as 36 horas, para as sementes do tratamento com água a $80^{\circ} \mathrm{C}$ das 12 até as 24 horas e nas sementes do tratamento com ácido sulfúrico $98 \%$ das 6 até as 10 horas, sendo esta a menor duração da fase II das três curvas de embebição realizada nesse trabalho. Destaca-se que o ganho de água também foi reduzido nessa etapa do processo de germinação, o controle teve um ganho de $2 \%$, água a $80{ }^{\circ} \mathrm{C} 16 \%$ e o tratamento com ácido sulfúrico $6 \%$.

A protrusão da raiz primária, indicativo do início da fase III da embebição, ocorreu em diferentes períodos para cada tratamento. Para as sementes não submetidas a nenhum tratamento de superação de dormência (controle), observamos que a protrusão da raiz primária das sementes ocorreu com cerca de 38 horas após o início da embebição, sendo necessário 166 horas para que ao menos $30 \%$ das sementes de M. flocculosa germinassem (Fig. 1).

Nas sementes submetidas a água aquecida a $80{ }^{\circ} \mathrm{C}$ por 10 minutos para a superação da dormência, a fase III iniciou 25 horas após o início da embebição e em 33 horas, mais de $75 \%$ das sementes já haviam germinado, enquanto as sementes submetidas à superação de dormência com ácido sulfúrico $98 \%$ por três minutos, iniciaram a fase III
11 horas após o início da embebição e com 18 horas mais de $80 \%$ das sementes já haviam germinado.

\section{Análise anatômica do tegumento}

Em relação à anatomia do tegumento das sementes de $M$. flocculosa verificamos que no início das fases I, o tegumento das sementes de todos os tratamentos se mostrava íntegro, com suas camadas celulares conservadas (Fig. 2 A, D e G). Observamos no tegumento dessas sementes a exotesta formada por células paliçádicas alongadas com a presença da linha lúcida, abaixo a mesotesta, com uma camada de osteosclereides seguida de várias camadas de células parenquimáticas.

Entretanto, no início da fase II podemos observar diferenças entre o tegumento das sementes submetidas aos diferentes tratamentos (Fig. 2 B, E e H), enquanto o controle manteve o tegumento conservado e próximo àquele observado no início da embebição, as sementes tratadas com água a $80^{\circ} \mathrm{C}$, apresentaram desorganização das células da exotesta e mesotesta em conjunto com fissuras na camada parenquimática. Já o tratamento para superação da dormência das sementes de M. floculosa, utilizando ácido sulfúrico 98\% levou a compactação das camadas celulares, enquanto as camadas mais externas, paliçádica e de osteosclereides, sofreram desorganização das paredes celulares.

Já no início da fase III (Fig. 2 C, F e I), observamos principalmente nas sementes de $M$. flocculosa que passaram pelos tratamentos com água a $80^{\circ} \mathrm{C}$ e ácido sulfúrico $98 \%$, uma desestruturação total da camada paliçada, formando espaços entre essa camada e a camada de osteosclereides. Destaca-se também que principalmente na mesotesta encontramos várias fissuras e espaços intercelulares após a utilização desses dois tratamentos. 

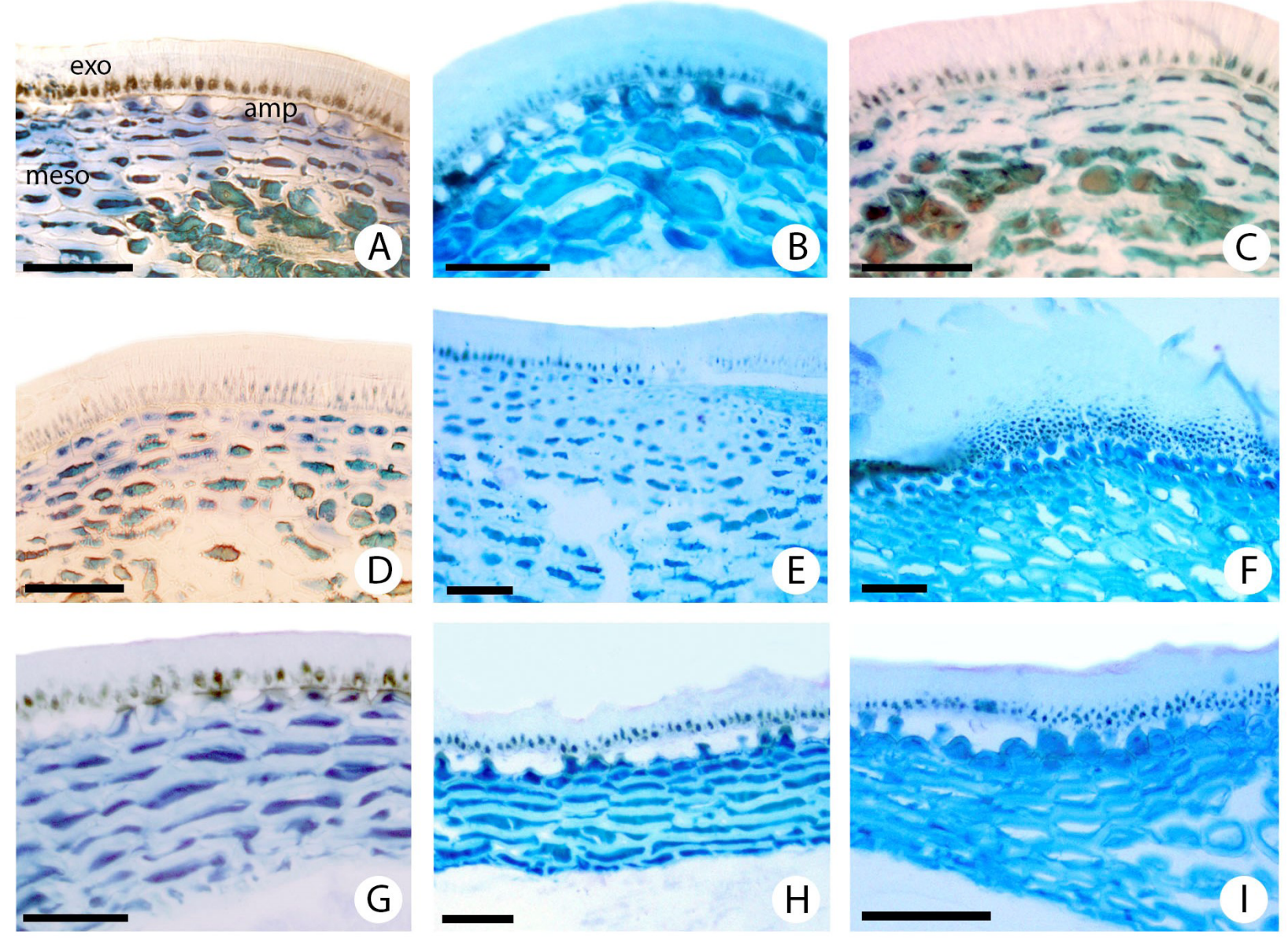

Figura 2. Anatomia do tegumento de sementes de Mimosa flocculosa durante o início da embebição, início da Fase II e início da Fase III em ordem crescente da evolução da curva de embebição, submetidas à tratamentos de superação de dormência. (A a C) Controle, (D a F) Água a $80{ }^{\circ} \mathrm{C}$ por 10 minutos e (G a I) Ácido Sulfúrico durante 3 minutos. exo = exotesta, amp = células em ampulheta, meso = mesotesta. Barras: Barras $=50 \mu \mathrm{m}$.

\section{Quantificação da mobilização de reservas}

Observamos que houve interação significativa entre os fatores (tratamentos para superação de dormência $x$ períodos da curva de embebição) para todas as reservas quantificadas nesse estudo (Tabs. 2 e 3 ).

Para a quantidade de açúcares solúveis totais (AST) (Tab. 2), entre os tratamentos, as sementes do controle mantiveram os maiores valores de AST, enquanto, aquelas que passaram pela água a $80^{\circ} \mathrm{C}$ durante 10 minutos tiveram diminuição marcante da concentração do AST ao longo da embebição, e as sementes onde foi aplicado o tratamento de superação de dormência com ácido sulfúrico $98 \%$, não diferiu nos períodos de coleta.

Letras iguais, maiúsculas para linhas (tratamentos) e letras minúsculas para as colunas (períodos de embebição), não diferem entre si pelo teste de Skott-Knott a 5\% de probabilidade.

Para os diferentes períodos de embebição em cada tratamento verificamos que, as sementes do controle apresentaram um comportamento crescente da concentração de AST, enquanto que para as sementes em que foi utilizado método de superação de dormência com água a $80^{\circ} \mathrm{C}$ houve um decréscimo, já para as que foi utilizado o tratamento com ácido sulfúrico $98 \%$ não houve diferença estatística na quantidade de AST.

Na quantificação da sacarose, entre os tratamentos utilizados, identificamos que o controle e o tratamento de superação de dormência com água a $80^{\circ} \mathrm{C}$ apresentaram as sementes com maiores concentrações, exceto no início e meio da fase II onde houve decréscimo da quantidade de sacarose, enquanto que o ácido sulfúrico apresentou as menores concentrações, exceto no meio da fase II. Durante os períodos de embebição, notamos que, as sementes do controle tiveram um decréscimo da concentração de sacarose iniciando no meio da fase II, as sementes submetidas ao tratamento com água a $80{ }^{\circ} \mathrm{C}$ diminuíram a concentração de sacarose a partir do início da fase II e as sementes do tratamento de superação de dormência com ácido sulfúrico $98 \%$ os valores diminuíram apenas no início da fase III (Tab. 2). 
Tabela 2. Quantificação de açúcares presentes nas sementes de Mimosa flocculosa Burkart, submetidas aos tratamentos durante os períodos da embebição: Início, meio da fase I, início da fase II, meio da fase II e início da fase III. Sendo então: controle ( $0 \mathrm{~h}, 8 \mathrm{~h}, 14 \mathrm{~h}, 26 \mathrm{~h}$ e $38 \mathrm{~h})$, Água a $80{ }^{\circ} \mathrm{C}$ por 10 minutos (0h, 6h, 12h, 18h e 25h) e ácido sulfúrico $98 \%$ por três minutos (0h, 3h, $6 \mathrm{~h}, 8 \mathrm{~h}, 11 \mathrm{~h})$.

\begin{tabular}{|c|c|c|c|}
\hline \multicolumn{4}{|c|}{ Açúcares } \\
\hline \multicolumn{4}{|c|}{ Açúcares Totais (AST) (mg/g) } \\
\hline $\begin{array}{c}\text { Tratamentos } \\
\text { Períodos de embebição }\end{array}$ & Controle & Água a $80^{\circ} \mathrm{C}$ & $\mathrm{H}_{2} \mathrm{SO}_{4} 98 \%$ \\
\hline Início da embebição & $85,34 \mathrm{Ad}$ & $85,97 \mathrm{Aa}$ & $84,23 \mathrm{Aa}$ \\
\hline Meio da fase I & $93,53 \mathrm{Ac}$ & $73,23 \mathrm{Cb}$ & $86,95 \mathrm{Ba}$ \\
\hline Início da fase II & $90,02 \mathrm{Ac}$ & $74,4 \mathrm{Bb}$ & $89,8 \mathrm{Aa}$ \\
\hline Meio da fase II & $116,6 \mathrm{Aa}$ & $75,01 \mathrm{Cb}$ & $88,12 \mathrm{Ba}$ \\
\hline Início da fase III & $109,13 \mathrm{Ab}$ & $59,41 \mathrm{Cc}$ & $88,98 \mathrm{Ba}$ \\
\hline C.V $(\%)$ & & $4,40 \%$ & \\
\hline \multicolumn{4}{|c|}{ Sacarose $(\mathrm{mg} / \mathrm{g})$} \\
\hline $\begin{array}{c}\text { Tratamentos } \\
\text { Períodos de embebição }\end{array}$ & Controle & Água a $80^{\circ} \mathrm{C}$ & $\mathrm{H}_{2} \mathrm{SO}_{4} 98 \%$ \\
\hline Início da embebição & $58,33 \mathrm{Aa}$ & $55,50 \mathrm{Aa}$ & $45,08 \mathrm{Ba}$ \\
\hline Meio da fase I & $58,2 \mathrm{Aa}$ & $55,10 \mathrm{Aa}$ & $47,33 \mathrm{Ba}$ \\
\hline Início da fase II & $61,21 \mathrm{Aa}$ & $49,05 \mathrm{Bb}$ & $47,2 \mathrm{Ba}$ \\
\hline Meio da fase II & $51,99 \mathrm{Ab}$ & $45,93 \mathrm{Bb}$ & $50,3 \mathrm{Aa}$ \\
\hline Início da fase III & $48,34 \mathrm{Ab}$ & $46,61 \mathrm{Ab}$ & $39,09 \mathrm{Bb}$ \\
\hline C.V (\%) & & $3,78 \%$ & \\
\hline \multicolumn{4}{|c|}{ Açúcares Redutores (AR) (mg/g) } \\
\hline $\begin{array}{c}\text { Tratamentos } \\
\text { Períodos de embebição }\end{array}$ & Controle & Água a $80^{\circ} \mathrm{C}$ & $\mathrm{H}_{2} \mathrm{SO}_{4} 98 \%$ \\
\hline Início da embebição & $0,207 \mathrm{Aa}$ & $0,187 \mathrm{Bb}$ & $0,200 \mathrm{Aa}$ \\
\hline Meio da fase I & $0,204 \mathrm{Aa}$ & $0,186 \mathrm{Bb}$ & $0,191 \mathrm{Bb}$ \\
\hline Início da fase II & $0,211 \mathrm{Aa}$ & $0,175 \mathrm{Bc}$ & $0,203 \mathrm{Aa}$ \\
\hline Meio da fase II & $0,217 \mathrm{Aa}$ & $0,177 \mathrm{Bc}$ & $0,208 \mathrm{Aa}$ \\
\hline Início da fase III & $0,208 \mathrm{Aa}$ & 0,206 Aa & $0,196 \mathrm{Ab}$ \\
\hline C.V $(\%)$ & & $5,80 \%$ & \\
\hline
\end{tabular}

Já os açúcares redutores (AR), (Tab. 2), apresentaram os menores valores dentre os açúcares analisados. Entre os tratamentos o controle apresentou valores de AR semelhantes aos observados nas sementes tratadas com ácido sulfúrico $98 \%$, exceto no meio da fase I, enquanto que o tratamento com água a $80^{\circ} \mathrm{C}$ por 10 minutos levou a reduções na concentração dos AR, exceto no início da fase III. Comparando os períodos de embebição, verificamos que o controle apresentou os maiores valores de AR, as sementes tratadas com água a $80{ }^{\circ} \mathrm{C}$ apresentaram os menores valores de $\mathrm{AR}$, com exceção no início da fase III onde houve um aumento neste tratamento, enquanto as sementes tratadas com ácido sulfúrico $98 \%$ apresentaram uma diminuição desses açúcares no meio da fase I e no início da fase III.

Com relação as proteínas (Tab. 3), para a concentração de albumina nas sementes, notamos que, entre os tratamentos durante a embebição, houve redução nas quantidades de albumina no início da embebição no tratamento com ácido sulfúrico $98 \%$ e elevação no início e meio da fase II para o tratamento com água a $80^{\circ} \mathrm{C}$.

Letras iguais, maiúsculas para linhas (tratamentos) e letras minúsculas para as colunas (períodos de embebição), não diferem entre si pelo teste de Skott-Knott a $5 \%$ de probabilidade.

Para os períodos de embebição em cada tratamento em relação a albumina, observamos que, no controle a partir do início da fase II apresentou decréscimo na sua concentração, para o método com água a $80{ }^{\circ} \mathrm{C}$ houve uma diminuição da albumina no início da embebição e início da fase III e para as sementes do tratamento com ácido sulfúrico $98 \%$ houve um aumento apenas no meio da fase I (Tab. 3).

Para a concentração de glutelina nas sementes (Tab. 3), observamos que, no tratamento de superação de dormência com água a $80^{\circ} \mathrm{C}$ durante o meio da fase I e início da fase II apresentou as maiores quantidades dessa proteína, e o controle no meio da fase II e início da fase III obteve maiores valores de albumina entre os tratamentos. Para os períodos de embebição em cada tratamento, o controle apresentou o maior valor de glutelina no início da fase III, a água a $80^{\circ} \mathrm{C}$ apresentou as maiores concentrações no meio da fase I e início da II e no método utilizando ácido sulfúrico $98 \%$ houve um decréscimo dos valores da glutelina ao longo os períodos de embebição nesse tratamento. 
Tabela 3. Quantificação das proteínas presentes nas sementes de Mimosa flocculosa Burkart, submetidas aos tratamentos por três minutos. Durante os períodos da embebição: Início, meio da fase I, início da fase II, meio da fase II e início da fase III. Sendo então: Controle (0h, 8h, 14h, 26h e 38h), Água a $80^{\circ} \mathrm{C}$ por 10 minutos (0h, 6h, 12h, 18h e $\left.25 \mathrm{~h}\right)$ e Ácido sulfúrico $98 \%$ por 3 minutos (0h, 3h, 6h, 8h, 11h).

\begin{tabular}{|c|c|c|c|}
\hline \multicolumn{4}{|c|}{ Proteínas } \\
\hline \multicolumn{4}{|c|}{ Albumina (mg/g) } \\
\hline $\begin{array}{c}\text { Tratamentos/ } \\
\text { Períodos de embebição }\end{array}$ & Controle & Água a $80^{\circ} \mathrm{C}$ & $\mathrm{H}_{2} \mathrm{SO}_{4} 98 \%$ \\
\hline Início da embebição & $2,14 \mathrm{Aa}$ & $1,79 \mathrm{Ab}$ & $1,4 \mathrm{Bb}$ \\
\hline Meio da fase I & $2,45 \mathrm{Aa}$ & $2,31 \mathrm{Aa}$ & $2,54 \mathrm{Aa}$ \\
\hline Início da fase II & $1,53 \mathrm{Bb}$ & $2,24 \mathrm{Aa}$ & $1,23 \mathrm{Bb}$ \\
\hline Meio da fase II & $1,49 \mathrm{Bb}$ & $2,1 \mathrm{Aa}$ & $1,52 \mathrm{Bb}$ \\
\hline Início da fase III & $1,69 \mathrm{Ab}$ & $1,8 \mathrm{Ab}$ & $1,48 \mathrm{Ab}$ \\
\hline C.V $(\%)$ & & $14,19 \%$ & \\
\hline \multicolumn{4}{|c|}{ Glutelina $(\mathrm{mg} / \mathrm{g})$} \\
\hline $\begin{array}{l}\text { Tratamentos / } \\
\text { Períodos de embebição }\end{array}$ & Controle & Água a $80^{\circ} \mathrm{C}$ & $\mathrm{H}_{2} \mathrm{SO}_{4} 98 \%$ \\
\hline Início da embebição & $2,87 \mathrm{Ab}$ & $2,76 \mathrm{Ab}$ & $2,79 \mathrm{Aa}$ \\
\hline Meio da fase I & $3,05 \mathrm{Bb}$ & $3,95 \mathrm{Aa}$ & $3,07 \mathrm{Ba}$ \\
\hline Início da fase II & $2,81 \mathrm{Bb}$ & $3,63 \mathrm{Aa}$ & $2,22 \mathrm{Cb}$ \\
\hline Meio da fase II & $3,1 \mathrm{Ab}$ & $2,09 \mathrm{Bc}$ & $1,98 \mathrm{Bb}$ \\
\hline Início da fase III & $3,71 \mathrm{Aa}$ & $0,95 \mathrm{Cd}$ & $1,56 \mathrm{Bc}$ \\
\hline C.V $(\%)$ & & $12,98 \%$ & \\
\hline \multicolumn{4}{|c|}{ Prolamina (mg/g) } \\
\hline $\begin{array}{c}\text { Tratamentos/ } \\
\text { Períodos de embebição }\end{array}$ & Controle & Água a $80^{\circ} \mathrm{C}$ & $\mathrm{H}_{2} \mathrm{SO}_{4} 98 \%$ \\
\hline Início da embebição & $0,9 \mathrm{Aa}$ & $0,59 \mathrm{Ba}$ & $0,87 \mathrm{Aa}$ \\
\hline Meio da fase I & $0,87 \mathrm{Aa}$ & $0,62 \mathrm{Ca}$ & $0,73 \mathrm{Bb}$ \\
\hline Início da fase II & $0,924 \mathrm{Aa}$ & $0,37 \mathrm{Cc}$ & $0,48 \mathrm{Bc}$ \\
\hline Meio da fase II & $0,47 \mathrm{Ac}$ & $0,39 \mathrm{Bc}$ & $0,45 \mathrm{Ac}$ \\
\hline Início da fase III & $0,78 \mathrm{Ab}$ & $0,46 \mathrm{Bb}$ & $0,51 \mathrm{Bc}$ \\
\hline C.V $(\%)$ & & $8,21 \%$ & \\
\hline \multicolumn{4}{|c|}{ Globulina (mg/g) } \\
\hline $\begin{array}{c}\text { Tratamentos } \\
\text { Períodos de embebição }\end{array}$ & Controle & Água a $80^{\circ} \mathrm{C}$ & $\mathrm{H}_{2} \mathrm{SO}_{4} 98 \%$ \\
\hline Início da embebição & $2,84 \mathrm{Aa}$ & $3,22 \mathrm{Aa}$ & $3,6 \mathrm{Aa}$ \\
\hline Meio da fase I & $2,87 \mathrm{Aa}$ & $3,71 \mathrm{Aa}$ & $1,64 \mathrm{Bb}$ \\
\hline Início da fase II & $3,48 \mathrm{Aa}$ & $3,77 \mathrm{Aa}$ & $2,98 \mathrm{Aa}$ \\
\hline Meio da fase II & $2,13 \mathrm{Aa}$ & $3,3 \mathrm{Aa}$ & $3,11 \mathrm{Aa}$ \\
\hline Início da fase III & $3,65 \mathrm{Aa}$ & $2,57 \mathrm{Aa}$ & $2,88 \mathrm{Aa}$ \\
\hline C.V $(\%)$ & & $26,20 \%$ & \\
\hline
\end{tabular}

Para a concentração de prolamina nas sementes (Tab. 3 ), constatamos que, entre os tratamentos durante os períodos de embebição, o tratamento utilizando água a $80^{\circ} \mathrm{C}$ apresentou as menores concentrações de prolamina do início da embebição até o meio da fase II, e no início da fase III as maiores quantidades de prolaminas entre os tratamentos foram encontradas no controle que diferiu significativamente dos tratamentos com água $80^{\circ} \mathrm{C}$ e ácido sulfúrico $98 \%$. Para os períodos de embebição em cada tratamento, houve decréscimo na quantidade de prolamina durante a embebição nos três tratamentos, para o controle esse decréscimo iniciou no meio da fase II, para o método utilizando água $80^{\circ} \mathrm{C}$ no início da fase II e para superação de dormência com ácido sulfúrico $98 \%$ a partir do meio da fase I.

Para a concentração de globulina, entre os tratamentos durante a embebição e entre os períodos de embebição em cada tratamento não houve diferenças estatísticas significativas, exceto no meio da fase I onde houve decréscimo na quantidade de globulina no tratamento com ácido sulfúrico $98 \%$. 


\section{Germinação das sementes de $M$. flocculosa}

Com relação a germinação (Fig. 3), observamos que, quando as sementes não são submetidas a um tratamento de superação de dormência, a germinação é 3 vezes mais baixa $(21 \%)$ comparadas as sementes que foram submetidas a tratamentos de superação de dormência com água aquecida (78\%), e 4 vezes mais baixa em relação as sementes submetidas ao ácido sulfúrico $98 \%$ (85\%).

A análise da frequência e sincronização de germinação (Fig. 3) demonstraram que a germinação da espécie estudada segue um padrão polimodal e espalhada ao longo do tempo (aproximadamente oito dias), quando não são submetidas à superação da dormência tegumentar. Já quando utilizamos os métodos de superação de dormência, há uma diminuição pela metade do tempo e tendência a um pico unimodal de germinação. E em relação a sincronização da germinação não houve diferença estatística entre os três tratamentos estudados.

\section{DISCUSSÃO}

Entre as curvas de embebição obtidas para as sementes de Mimosa flocculosa (Fig. 1), a curva do controle foi a que mais se diferenciou do padrão trifásico proposto por Bewley et al. (2013), reforçando que, as sementes de $M$. flocculosa possuem dormência física, e como estavam com seu tegumento intacto, o ganho de água foi mais lento e desuniforme. Característica encontrada em grande parte das espécies da família Fabaceae que possuem dormência ocasionada pela presença de um tegumento rígido, devido às camadas celulares com paredes espessadas presente nas sementes que conferem a impermeabilidade e resistência a entrada de água (Matos et al. 2015).
Observamos que, a fase I nas sementes de M. flocculosa (Fig. 1) que passaram pelo tratamento de superação de dormência com ácido sulfúrico $98 \%$ foi mais rápida do que os outros tratamentos, já que, na fase I ocorre elevada entrada de água devido à diferença de potencial entre a semente e o substrato onde ela se encontra, quando não há impedimentos físicos, o uso de ácido permitiu a entrada de água nas sementes formando as fissuras, ocorrendo o influxo de água nessas sementes (Molizane 2012, Bewley et al. 2013).

Em nosso trabalho, observamos que as sementes sem nenhum tratamento necessitaram de 13 horas a mais do que as sementes que passaram por superação de dormência com água a $80^{\circ} \mathrm{C}$ e de 27 horas a mais do que as sementes submetidas ao ácido sulfúrico $98 \%$ nesta fase. De acordo com Ferreira \& Borghetti (2004), como a fase II é de estabilização e a hidratação das sementes se torna mais lenta, as sementes que possuem dormência apresentam essa fase prolongada em comparação as que não apresentam dormência.

Na fase III da embebição (Fig. 1), observamos que, nas sementes de M. flocculosa em que foram utilizados tratamentos de superação de dormência, houve maior incremento no teor de água e massa dessas sementes devido a elevada germinação. Com o uso desses tratamentos foram formadas fissuras no tegumento e até mesmo a retirada de camadas celulares nas sementes (Fig. 2 F e I), permitindo a entrada de água e germinação elevada quando comparadas com o controle. Resultados semelhantes foram encontrados em sementes de Macroptilium martii Benth no qual Araújo et al. (2014), obtiveram $74 \%$ de sementes germinadas em sua curva de embebição utilizando ácido sulfúrico durante três minutos.
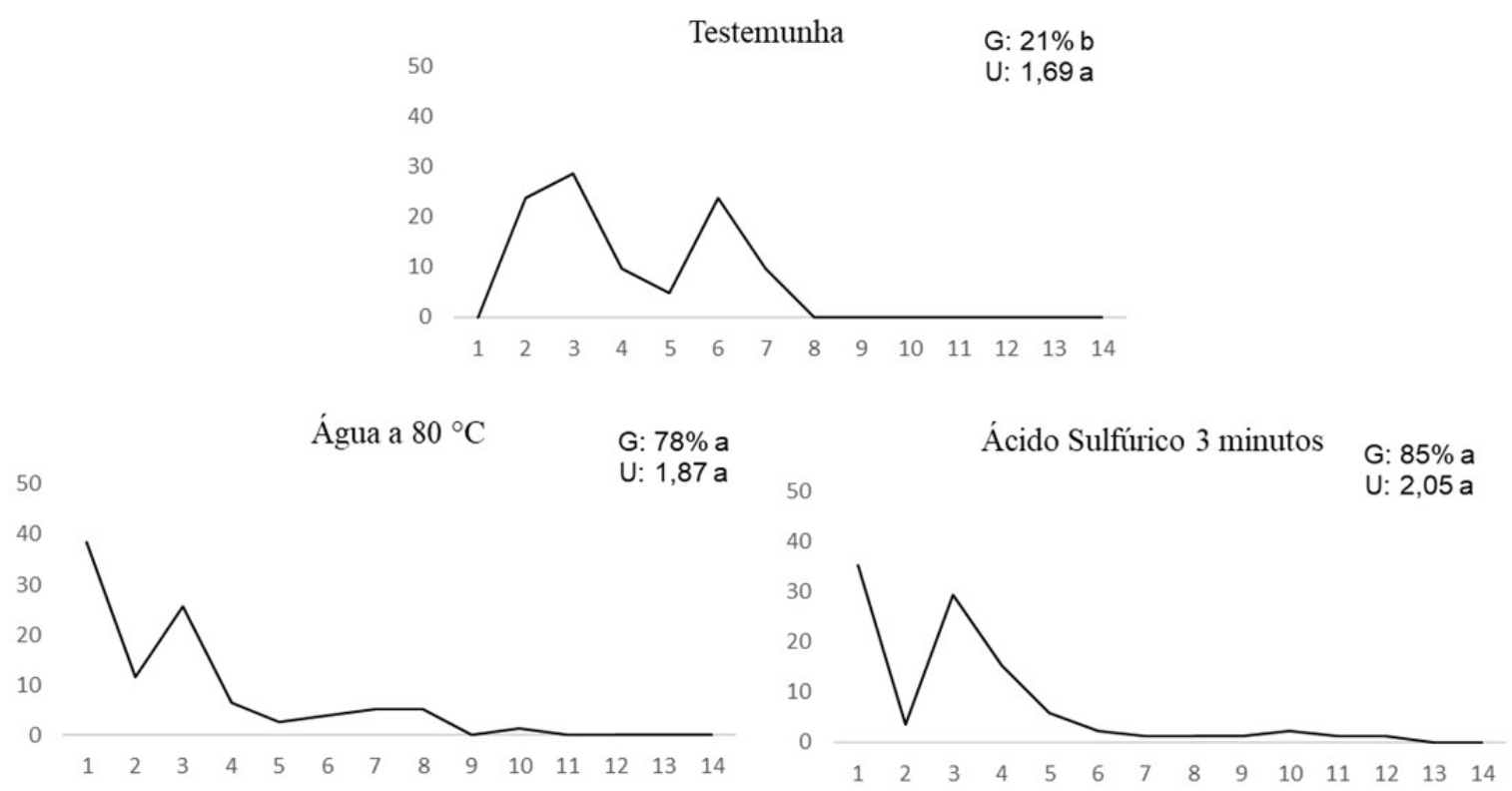

Figura 3. Frequência relativa da germinação das sementes de Mimosa flocculosa submetidas aos tratamentos "controles", "água a $80{ }^{\circ} \mathrm{C}$ e "ácido sulfúrico 98\%”, durante quatorze dias. G= Porcentagem média de sementes germinadas (\%) e U= sincronização da germinação. 
Em nosso trabalho verificamos que, nos dois tratamentos de superação de dormência utilizados, os tempos da curva de embebição foram menores em comparação com o controle, auxiliando assim, que a germinação ocorresse mais rapidamente e em maior valor (Figs. 1 e 3). Essa diminuição do tempo pode ser explicada de acordo com Nogueira et al. (2019) que, quando aplicamos diferentes métodos de superação de dormência, as sementes podem alongar ou diminuir o tempo durante as fases da embebição.

Quando aplicamos o método de superação de dormência com água aquecida, isso ocorre devido a alteração no número de pontes de hidrogênio formadas entre os polissacarídeos da parede, principalmente entre microfibrilas de celulose, causando a diminuição da concentração destes polissacarídeos, facilitando a entrada de água, devido ao rompimento da barreira física (Dapont et al. 2014).

Já quando utilizamos o método de superação de dormência com ácido sulfúrico sua eficiência, comprovada nesse trabalho, ocorre devido à sua ação abrasiva, onde há desgaste no tegumento celular, até a exposição das camadas mais internas, resultando na formação de lacunas que permitem o influxo de água nas sementes auxiliando também na germinação (Castro et al. 2017).

Da mesma forma, em trabalhos como de Molizane (2012) e Ribeiro et al. (2016), que sementes de Erytrhina speciosa Andrews e Peltophorum dubium (Spreng.) Taub. respectivamente, tiveram alterações anatômicas em seu tegumento após passarem pelo tratamento com ácido sulfúrico, refletindo em maior germinação. Também Castro et al. (2017), estudando sementes de Apuleia leiocarpa (Vogel) J.F. Macbr, quando utilizaram o tratamento com água a $80{ }^{\circ} \mathrm{C}$ durante 30 segundos, observaram fissuras e enfraquecimento do tegumento, porém, nestas sementes não houve incremento de germinação. Esses estudos demonstraram mais uma vez que as espécies possuem respostas diferentes aos tratamentos e, por isso, a necessidade de estudos aprofundados.

Em relação a mobilização de reserva (Tabs. 2 e 3), a respiração das sementes se inicia pela glicólise, desencadeada pelo uso dos açúcares de reserva (AST, AR e sacarose), que atuam como compostos de reserva rápida e são os primeiros a serem degradados durante a embebição. Porém, os açúcares não servem apenas para a síntese de energia, mas também produzem compostos intermediários que auxiliam no desenvolvimento posterior da plântula (Buckeridge et al. 2004; Corte et al. 2006).

Nas sementes de M. flocculosa (Tab. 2), verificamos que entre os tratamentos, os maiores valores de AST foram encontrados no controle, podendo ser pelo fato de que a água entrou devagar nessas sementes tornando a mobilização de reservas mais lenta, necessitando de maior tempo para aumentar as atividades metabólicas e, com isso, a germinação. Já nas sementes submetidas aos dois tratamentos de superação de dormência, observamos um decréscimo na concentração de AST entre os tratamentos durante a embebição, demonstrando que estes tratamentos conseguiram mobilizar mais açúcares, acarretando em uma rápida e uniforme germinação (Gama et al. 2011).

A sacarose (Tab. 2) é o açúcar mais abundante nas plantas, sendo o principal transportado, é um carboidrato com rápida disponibilidade (Jose et al. 2006). E dentre os tratamentos em nosso trabalho, observamos que principalmente a água a $80{ }^{\circ} \mathrm{C}$ e o ácido sulfúrico $98 \%$ apresentaram decréscimo da concentração de sacarose durante a embebição, indicativo de utilização no processo germinativo.

Observamos que, nos tratamentos de superação de dormência houve diminuições dos açúcares redutores (Tab. 2). Fornecendo indícios que os AR auxiliaram na diminuição dos processos oxidativos danosos, causados pela desestruturação no tegumento das sementes, provocada pelos tratamentos de superação de dormência (Fig. 2, E, H, F e I). Uma vez que os açúcares redutores são carboidratos doadores de elétrons, reduzindo os agentes oxidantes nas sementes (Castellión et al. 2010)

Em relação às proteínas (Tab. 3), a principal função nas sementes é de armazenar principalmente nitrogênio e enxofre, que são utilizados para a síntese de outras proteínas, corpos proteicos e ácidos nucleicos que serão utilizados durante o processo de embebição ou o desenvolvimento das plântulas, mas as proteínas também servem como fonte de energia para o eixo embrionário, sendo convertidas em aminoácidos, transformadas em $\alpha$-cetoglutarato, entrando no ciclo de Krebs fornecendo também ATP necessário para a respiração (Buckeridge et al. 2004, Sert et al. 2009).

Para a albumina, observamos oscilações da concentração entre os tratamentos e durante os períodos de embebição, semelhante ao descrito por Dantas et al. (2008), estudando sementes de Schinopsis brasiliensis Engl., que também observaram oscilações desta proteína durante a embebição, podendo ser resultado principalmente da utilização desta proteína na reidratação e biossíntese de enzimas chaves para a germinação.

Verificamos diminuição da glutelina nos tratamentos de superação de dormência principalmente na fase II e III, onde é necessária grande quantidade produção de ATP, sendo utilizado os açúcares e as proteínas, tornando o metabolismo altamente ativo possibilitando a germinação. Em geral, a glutelina é uma das proteínas de reserva encontrada em grande concentração nas sementes (MarcosFilho 2015), em nosso trabalho ela foi a segunda proteína mais encontrada (Tab. 3).

Em nosso trabalho as sementes de $M$. flocculosa apresentaram baixas concentrações de prolamina, porém também foram utilizadas durante a embebição, principalmente nos tratamentos de superação de dormência (Tab. 3). As prolaminas são encontradas associada ao amido nos cereais, dessa forma a maioria das leguminosas apresentam baixas concentrações desta proteína (Souza et al. 2012). Como observado por Rodrigues et al. (2019), onde as sementes de Aspidosperma polyneuron Mül.Arg. se mantiveram com baixos valores dessa proteína. 
A globulina foi a proteína encontrada em maior quantidade (Tab. 3), sendo que todos os valores entre os tratamentos se mostraram elevados. Foi observado por pesquisadores como Silva et al. (2001) e Neves et al. (2004) que em sementes de leguminosas, as globulinas são as proteínas mais abundantes. A globulina é a proteína com maior acúmulo de aminoácidos essenciais que auxiliam após a germinação na diferenciação dos tecidos e órgãos nas plântulas, um dos motivos para não observarmos grandes alterações durante a embebição (Ribeiro 2007).

Em relação a germinação, frequência e sincronização da germinação (Fig. 3), podemos observar que, as sementes intactas de $M$. flocculosa possuem um tegumento rígido que dificulta a entrada de água e oxigênio e quando aplicamos os dois métodos de superação de dormência, ambos auxiliaram na germinação. Como observado no trabalho de Albuquerque et al. (2007), as sementes de Bowdichia virgilioides Kunth apresentaram os maiores valores para germinação após passar pelo tratamento com ácido sulfúrico durante 4 minutos e $71 \%$ de sementes germinaram, e Paulino et al. (2004), estudando métodos de superação de dormência para sementes de Leucaena leucocephala (Lam) de Wit, observaram que o uso de água aquecida a $80^{\circ} \mathrm{C}$ incrementou a germinação em $70 \%$.

Com isso, em nosso trabalho observamos que, as sementes de M. flocculosa que passaram pelos métodos de superação de dormência com água a $80^{\circ} \mathrm{C}$ por 10 minutos e ácido sulfúrico por três minutos, obtiveram uma curva de embebição mais uniforme e mais semelhante com a curva de perfil trifásico, devido à formação de fissuras nas camadas do tegumento, auxiliando na rápida entrada de água. E, também nesses tratamentos, com a rápida entrada de água, os açúcares tiveram uma redução mais proeminente durante os períodos da embebição em conjunto com as albuminas, glutelinas e prolaminas, sendo que essas reservas degradadas fornecem a energia necessária para o metabolismo das sementes fazendo com que a germinação ocorra.

Sintetizando nossos resultados, os tratamentos utilizando água a $80^{\circ} \mathrm{C}$ por 10 minutos e ácido sulfúrico por 3 minutos, são eficientes e indicados para a superação de dormência nas sementes de Mimosa flocculosa, pois conseguem modificar o tegumento, auxiliando na entrada de água em conjunto com uma rápida mobilização de reservas, fornecendo energia necessária para uma elevada e uniforme germinação garantindo o sucesso na germinação e consequentemente na produção de mudas.

\section{AGRADECIMENTOS}

O presente trabalho foi realizado com apoio da Coordenação de Aperfeiçoamento de Pessoal de Nivel Superior - Brasil (CAPES) - Código de Financiamento 001 e também agradecemos ao Instituto Ambiental do Paraná pela doação das sementes utilizadas.

\section{REFERÊNCIAS}

Albuquerque, K.S., Guimarães, R.M., Almeda, I.F. \& Clemente A.C.S 2007. Métodos para a superação da dormência em sementes de sucupira-preta (Bowdichia virgilioides Kunth). Revista Brasileira de Ciências Agrárias 31(6):1716-1721.

Alexandre, R.S., Gonçalves, F.G., Rocha, A.P., Arruda, M.P. \& Lemes, E.Q. 2009. Tratamentos físicos e químicos na superação de dormência em sementes de Enterolobium contortisiliquum (Vell.) Morong. Revista Brasileira de Ciências Agrárias 4(1):156-159.

Araújo, R.F., Zonta, J.B., Araújo, E.F., Donzeles, S.M.L. \& Costa, G.M 2014. Curva de absorção de água em sementes de pinhão-manso (Jatropha curcas L.). Idesia 32(2):27-32.

Baskin, J.M. \& Baskin, C.C. 2004. A Classification System for Seed Dormancy. Seed Science Research 14(1):1-16.

Brasil, 2013. Ministério da Agricultura, Pecuária e Abastecimento. Instruções para Análise de Sementes de Espécies Florestais. Brasília: MAPA/ACS.

Bewley, J.D., Bradford, K.J., Hilhorst, H.W.M. \& Nonogaki, H. 2013. Seeds: physiology of development and germination. Springer 3002p.

Bradford, M.M. 1976. A rapid and sensitive method for the quantification of Microgram quantities of protein utilizing the principle of proteindye binding Analytical Biochemistry 72: 248-254.

Buckeridge, M.S. 2004. Acúmulo de Reservas. In: Ferreira, A.G.; Borghetti, F. Germinação: do básico ao aplicado. Porto Alegre: Artmed $324 \mathrm{p}$.

Castellión, M. Matiacevich, S. Buera, P. \& Maldonado, S. 2010. Protein deterioration and longevity of quinoa seeds during long-term storage. Food Chemistry 121: 952-958.

Castro, D.S.A., Araujo, E.F., Borges, E.E.L. \& Amaro, H.T.R. 2017. Caracterização da testa de sementes de Apuleia leiocarpa (Vogel) j. f. Macbr) após superação de dormência. Ciência Florestal 27(3):10611068.

Cardoso, V.J.M. 2009. Conceito e classificação da dormência em sementes. Oecologia Brasiliensis 13(4):619-631.

Carvalho, N.M. \& Nakagawa, J. 2012. Semente: Ciência, Tecnologia e produção, Editora Funep Jaboticabal, 590p.

Corte, V.B., Borges, E.E.L., Pontes, C.A., Leite, I.T.A., Ventrella, M.C., \& Mathias, A.A. 2006. Mobilização de reservas durante a germinação das sementes e crescimento das plântulas de Caesalpinia peltophoroides Benth. (Leguminosae-Caesalpinoideae). Revista Árvore 30(6):941-949.

Dantas, B.F., Silva, F.F.S., Lopes, A.P. \& Drummond M.A. 2008. Tecnologia de sementes de pinhão manso (Jatropha curcas): avaliações iniciais da qualidade fisiológica. Disponível em:www. biodiesel.gov.br/docs/congresso1007/agricultura/69.pdf.

Dapont, E.C., Silva, J.B., Oliveira, J.K., Alves, C.Z. \& Dutra, A.S. 2014. Métodos para acelerar e uniformizar a emergência de plântulas de Schizolobium amazonicum. Revista Ciência Agronômica 3(1):598605.

Ferreira, G. \& Borghetti, F. 2004. Germinação: do básico ao aplicado. Porto Alegre Artimed. 324p.

Fonseca, C.R. \& Venticinque, C.A. 2018. Biodiversity conservation gaps in Brazil: a role for systematic conservation planning. Perspectives in ecology and conservation 16(2):61-67.

Furtado, Aldol. 2014. Mobilização de reservas e partição de metabólitos durante a germinação da semente e o estabelecimento da plântula em moringa. Dissertação 39 f., Universidade Federal do Rio Grande do Norte, Natal, 2014.

Gama, J.S.N., Alves, E.U., Bruno R.L.A., Pereira, L.R.J., Braga J.M.J. \& Monte, D.M. 2011. Superação de dormência em sementes de Centrosema plumieri benth. Revista Brasileira de Sementes 33(4):643-651.

Garcia, I.S., Souza, A., Barbedo, J.C., Dietrich. S.M., \& FigueiredoRibeiro, R.C. 2006. Changes in soluble carbohidrates during storage of Caesalpinea echinata Lam. (brazil wood) seeds, an endangered Leguminous tree from the brazilian atlantic forest. Brazilian Journal of Biology 66(2):739-745. 
Hadas, A. 1976. Water uptake and germination of leguminous seeds under changing external water potential in osmotic solution. Journal of Experimental Botany 27(1):480-489.

Johansen, D.A. 1940. Plant microtechnique, McGraw- Hill Book New York, 487p.

José, S.C.B.R., Von Pinho, E.V.R. \& Dias, M.A.G.S. 2006. Açúcares e tolerância à alta temperatura de secagem sementes de milho. Revista Brasileira de Sementes 28(2):60-68.

Kageyama, P.Y., Sebbenn, A.M., Ribas, LA, Gandara FB, Castellen M, Perecin MB, Vencovsky R 2003. Diversidade genética em espécies arbóreas tropicais de diferentes estágios sucessionais por marcadores genéticos. Scientia Forestalis 64:93-107.

Labouriau, L.G. \& Valadares, M.E.B. 1976. On the germination of seeds Calotropis procera (Ait.) Ait.f. Anais da Academia Brasileira de Ciências 48(2):263-284.

Marcos-Filho, J. 2015. Fisiologia de sementes de plantas cultivadas Londrina, Abrates, $659 \mathrm{p}$.

Matos, A.C.B., Ataide, G.M. \& Borges, E.E.L. 2015. Physiological, physical, and morpho-anatomical changes in Libidibia ferrea ((Mart. ex Tul.) L.P. Queiroz) seeds after overcoming dormancy. Journal of Seed Science 37(1):026-032.

Miller, G.L. 1959. Use of dinitrosalicylic acid reagent for determination of reducing sugar. Analytical Biochemistry 31(1):426-428.

Molizane, D.M. 2012. Estabelecimento e superação de dormência em sementes de Erythrina speciosa Andrews, Dissertação de Mestrado, Câmpus de Botucatu, UNESP, São Paulo, 77p.

Monteiro, L., Machado, N., Martins, E., Pougy, N., Verdi, M., Martinelli, G.\& Loyola, R. 2018. Conservation priorities for the threatened flora of mountaintop grasslands in Brazil. Flora 238(1):234-243.

Morris, D.L. 1948. Quantitative determination of carbohydrates with Dreywood's anthrone reagent. Science 107(1):111-114.

Neves, V.A., Silva, M.A. \& Lourenço, E.J. 2004. Caracterização e hidrólise in vitro da globulina principal de grão-de-bico (Cicer arietinum L.), Marrocos. Ciência e Tecnologia de Alimentos 24(1):139-141.

Nogueira, N.W., Torres, S.B., Freitas, R.M.O., Leite, M.S. \& Paiva, E.M. 2019.Aspectos físicos e fisiológicos em sementes de Mimosa ophthalmocentra Mart. ex Benth. Revista Ciências Agrárias 42(3):666-675

O'Brien, T.P., Feder, N. \& Mccully, M.E. 1964. Polychromatic staning of plant cell walls by toluidine blue. Protoplasma 59(1):368-373.

Oliveira, A.B. \& Bosco, M.R.O. 2013. Biometria, determinação da curva de absorção de água em sementes e emergência inicial de plântulas de Copernicia hospita Martius. Revista Brasileira de Agroecologia 8(1):66-74.

Paulino, V.T., Freitas, J.C.T., Junior, C.R., Dalle-Vedove, D.J.F. Souza, C.F.J. \& Natal, V. 2004. Escarificação de sementes de leucena (Leucaena leucocephala (Lam.) de Wit) cultivares Cunnighan e Piracicaba. Revista Científica Eletrônica de Agronomia 6(1):4-8.

Passos, L.P. 1996. Métodos analíticos e laboratoriais em fisiologia vegetal. Coronel Pacheco: EMBRAPA - CNPGL 223pp.

Ribeiro, E.S. 2007. Efeitos de proteínas do tipo vicilina, ligantes de insulina, sobre o desenvolvimento de plântulas de Canavalia ensiformis (Fabaceae), Dissertação de Mestrado, Universidade Estadual do Norte Fluminense Darcy Ribeiro - UENF, Rio de Janeiro, $102 \mathrm{p}$.

Ribeiro, M.I., Muller, E.V., Porto, E., Santos, J.A., Fortes, A.M.T., Martins, S., \& Corsato, J.M. 2016. Alterações no tegumento de sementes de Peltophorum dubium (Sprengel) Taubert submetidas a tratamentos de superação de dormência. Journal of Agronomic Sciences 5(2):158-169.

Rodrigues, G.A.G., Ribeiro, M.I., Luz, E.M.Z., Porto, E.C., Matias, G.L., Corsato, J.M. \& Fortes, A.M.T. 2019. Drought stress effects on germination and reserve degradation of Aspidosperma polyneuron seeds. Revista Brasileira de Ciências Agrárias 14(4): 1-10.

R Studio Team 2015. RStudio: Integrated Development for $R$. RStudio, Inc., Boston, MA.

Sert, M.A., Bonato, C.M. \& Souza, L.M. 2009. Germinação da Semente. In: Souza, L. A. (Org.) Sementes e Plântulas: Germinação, Estrutura e Adaptação. Ponta Grossa, PR: Toda Palavra 98p.

Silva, M.A., Neves, V.A. \& Lourenço, E.J. 2001. Frações protéicas e globulina principal de grão-de-bico (Cicer arietinum L.), Marrocos. Alimentos e Nutrição 12(1)131-149.

Souza, L.C.D., Sá, M.M., Moraes, S.M.B., Carvalho, M.A.C., Silva, M.P. \& Abrantes, F.B. 2012. Composição química e nutrientes em sementes das espécies florestais pente de macaco, flor de paca, itaúba, jatobá e murici manso. Bioscience Journal 28(3):478-483.

Shibata, M., Oliveira, L.M., Pavelski, L.G. 2014. Avaliação da qualidade fisiológica de sementes de Mimosa flocculosa de diferentes colorações submetidas a tratamentos pré-germinativos. Revista de Ciências Agroveterinárias 13(1):40-46.

Shibata, M., Pavelski, L.G., Miranda, L., Oliveira, M.L. 2017. Germinação de sementes de Mimosa flocculosa. Magistra. 28(1):131-136.

Suda, C.N.K. \& Giorgini, J.F. 2000. Seed composition and mobilization during germination and initial seedling development of Euphorbia heterophylla. Brazilian Journal of Plant Physiology.12(3): 226-245. 